\title{
Reimagining Universal Health Coverage: Safe and Affordable Surgery
}

\author{
Minsol Kim" \\ Kee Bum Park \\ Sangchul Yoon ${ }^{\text {wat }}$
}

\begin{abstract}
UN sustainable development goals (SDGs) and universal health coverage (UHC) are significant health goals the world needs to achieve. Despite concerted efforts to attain UHC, the world is still lagging. Compared to the sizable number of resources put into the treatment of well-known communicable diseases, such as HIV/AIDs, tuberculosis, and malaria, surgery is relatively underutilized despite its potential. Scaling up surgical interventions, however, is crucial since it can save many people's lives and help avert the economic losses incurred due to diseases.
\end{abstract}

\footnotetext{
* Main author: Researcher, Yonsei Institute for Global Health, Yonsei University Health System ** Co-author: Lecturer, Program in Global Surgery and Social Change, Harvard Medical School *** Corresponding author: Associate Professor, Department of Medical Humanities and Social Science, College of Medicine, Yonsei University / littleluke22@yonsei.ac.kr

(c) Copyright Korea International Cooperation Agency. This is an Open-Access article distributed under the terms of the Creative Commons Attribution Non-Commercial License (http://creativecommons.org/ licenses/by-nc/4.0/) which permits unrestricted non-commercial use, distribution, and reproduction in any medium, provided the original work is properly cited.
} 
Moreover, increased surgical capacity in low-to-middle-income countries (LMICs) could prove useful in overcoming pandemics, such as COVID-19. To upgrade the surgical capacity of the LMICs, it is essential to incorporate National Surgical, Obstetric, and Anaesthesia Plans (NSOAPs) into their national health policies. In this paper, the illustrative cases of two countries that adopted NSOAPs with a different model. Zambia and Pakistan, are examined. We conclude by giving recommendations to countries that are yet to adopt NSOAPs.

Key words: Sustainable Development Goals, Universal Health Coverage, Surgical Obstetric Anaesthesia Care, Health Equity, National Surgical, Obstetric, Anaesthesia Plan (NSOAPs) 


\section{I . INTRODUCTION}

Strengthened health system is a foundation for universal health coverage (World Health Organization, 2021b). For UHC to be genuinely inclusive, a transition must be made from health systems organized around diseases and institutions towards health systems for people. This is the goal of the sound health system as the primary health care system underlies the commitment to social justice, equity, solidarity and participation (World Health Organization, 2021a). It is founded on the notion that the enjoyment of the highest attainable standard of health is one of every human being's fundamental rights (World Health Organization, 2021a). Thus, strengthened health system is rendered more crucial necessity for UHC.

The world has been stricken hard by the COVID-19 pandemic. However, the value of stable health system has never been more evident. While progress has been made in primary health care, more solid policies, and more socially encompassing participation are all necessary for UHC. WHO stated that member nations are falling behind in attaining the 2019 UN General Assembly's aim of UHC for everyone in the world by 2030. Despite progress in average levels of service coverage, 710 million people still lack access to health services, compared to the aim of 1 billion people benefiting from UHC (Prince, 2021). According to Tedros, the Director General of WHO, "the world is far behind."

Surgical care is one of the topics which have been largely overlooked in the global health sector (Farmer, 2008). Despite the concerted efforts of the world's governments and individuals to bring about UHC, it has allocated relatively little time and attention in improving surgical care than it has in other sectors. Regardless of the fact that surgery can address a substantial proportion of the world's critical public health problems, the value of surgical treatments is yet to be fully appreciated, but rather treated as the "neglected stepchild of global health" (Farmer, 2008). Undeniably, however, surgical care is an indispensable component of UHC (Roa, et al., 2019). It is estimated that surgical intervention is required for one-third of the global burden of disease. Every year, 18 million people die from surgically treatable diseases (Meara \& Greenberg, 2015b). Furthermore, potential deaths avoidable by surgery and anesthesia (16.9 million in 2010) exceed historical communicable disease deaths including tuberculosis (1.2 million), HIV (1.46 
million) and malaria (1.17 million) combined (National Academies of Sciences, Engineering, and Medicine, 2017). In spite of the great need and potential impact of the global surgery movement, when comparing to the Global Fund for HIV, Malaria, and TB, which has an annual budget of over $\$ 4$ trillion, the funding for surgical, obstetrical and anaesthesia has no similar mechanism (Global Surgery Foundation, n.d.). Furthermore, despite the significant worldwide burden of surgical diseases, surgery and anesthesia are overlooked in many national health policies and plans (Truché et al., 2020).

One reason surgery is continuously discounted in the global agenda is due to the myth that surgery is costly. This misguided perception acts as an impediment to universal acceptance of its potential role in accomplishing global health goals, specifically when compared with other public health measures such as vaccines or antiretroviral treatment. The uncertainty about efficacy of surgical intervention in the prevention of death and disability, and recognized criteria for surgical care quality call into doubt the value of surgery in such a setting (Chao et al., 2014).

To make matters worse, there is a clear disparity in surgical capacity between high-income and low-and middle-income countries (LMICs). In comparison to United Kingdom, which has 14.7 theatres and 30.5 general surgeons per 100,000 people, Kenya has 1.1 theatre and 0.55 general surgeon per 100,000 people (Dell, 2016). Only $3.5 \%$ of the 234 million surgeries conducted each year are performed in the world's poorest regions, which spend less than $\$ 100$ per capita on health care, but accounting for $34.8 \%$ of the worldwide population (Weiser, 2008). This consequential equity gap must be bridged by expanding people's access to critical surgical treatment (United Nations Institute for Training and Research, UNITAR, 2020). After recognizing the need to reduce such gaps, the Lancet Comission on Global Surgery (LCoGs) recommended the development of the National Surgical, Obstetric, Anaesthesia Plan (NSOAPs) in 2015 to systematically respond to them (Peck \& Hanna, 2018b). NSOAPs are strategic plans to increase access to essential surgical services by incorporating them into the broader national health plans and UHC benefits packages which are critical to ensure national implementation and scale (UNITAR, 2020).

This article intends to accentuate the need for LMICs to integrate NSOAPs into 
their national health policy in order to deal with the health equity gaps. It argues that Surgical Obstetric and Anaesthesia (SOA) care should be prioritized through the establishment of NSOAPs, as doing so is indispensable to achieving the United Nations Sustainable Development Goals (SDGs) and UHC. The paper will consider what NSOAPs is and then study the cost incurred from maintaining the status quo if the world does not adopt NSOAPs. We will then take a look at the cases of Zambia and Pakistan and how these countries incorporated NSOAPs into the national health plans, which will serve as examples. Lastly, the significance of NSOAPs will be analyzed and suggestions for other countries that are yet to adopt the NSOAPs will be made.

\section{What IS NSOAPs AND WHAT DOES IT DO?}

Many LMICs have devised systematic plans to integrate surgery into national health goals. These goals aim to help nations or regions in identifying and closing gaps as they work toward reaching the fundamental surgical standards required to offer UHC and meet WHA 68.15 commitments by 2030 (Peters et al., 2020). The NSOAP process is critical because it provides the knowledge foundation, technical competence, and political capital required to incorporate a contextualized surgical package inside UHC. Typically, the establishment of NSOAPs is overseen by ministries of health. The procedure prioritizes inclusiveness and accountability, with participation from all key stakeholders who will be impacted by the policy (Citron et al., 2018; Nyberger et al., 2018). Its inclusive and transparent characteristics serve to attract political support, create legitimacy, decrease policy opposition, and increase acceptance of the health system reform endeavor. The process also includes the participation of technical experts from various disciplines such as public health, economics, and health policy, as well as clinicians and epidemiologists in order to generate the evidence and knowledge needed to address health system gaps in workforce, infrastructure information systems, service delivery, information management, and governance (Nyberger et al., 2018).

The NSOAPs framework offers a systematic approach to improving surgical systems by addressing five health-care domains. Equipping five domains of the 
NSOAPs accordingly will aid in the integrations of safe, timely and affordable surgical, obstetric and anesthesia care in the LMICs.

\section{Five Component Framework of NSOAPs}

\section{1) Infrastructure}

Plethora of studies demonstrate that existing health facilities lack the fundamental infrastructure needed to provide surgical services. For example, a countrywide survey done in 2012 discovered that just 33\% of Tanzanian health centers and $51 \%$ of hospitals providing surgical services had the necessary personnel and equipment for safe surgical procedures (SARA, 2013). By updating current health facilities with the appropriate infrastructure and including the essential supplies required for safe surgical procedures, the NSOAP framework will keep the focus on delivering safe surgical services for the patients' specific levels of care. To satisfy the recommendations of the NSOAPs, most of the operating theaters in all health institutions of LMICs are to be restored and renovated (Citron et al., 2019).

\section{2) Workforce}

To improve the density of physician specialist SOA providers, the NSOAP framework is designed to raise the total number of specialist SOA providers to 2.27 providers per 100,000 population by 2025 (Citron et al., 2019). The SOA provider density in Tanzania being 0.46 per 100 population, for example, shows how LMICs fall short of the recommended level of 20 per 100,000 population (World Bank, 2015). In Tanzania's case, addressing the workforce shortage will require training an additional 240 surgeons, 567 anaesthesiologists and 200 obstetricians (Citron et al., 2019). Furthermore, the strategy should push for local specialized training through the establishment of regional training centers to encourage clinicians to practice where they learn, which has been shown to enhance local retention (Gyedu, 2017). 


\section{3) Information management}

In LMICs, there is little data on SOA systems. Decision-making, accountability and advocacy from the facility level to the national level is contingent on available data. According to NSOAP framework, the four WDIs pertaining to surgery - number of surgical procedures, specialist surgical workforce, risk of catastrophic expenditure for surgical care, risk of impoverishing expenditure for surgical care - must be reported at the minimum. It is advised that facility-level surgical multidisciplinary teams meet on a regular basis to evaluate and discuss the information gathered on the SOA system. Mortality and morbidity evaluations as well as the establishment of an action plan for facility data will be a part of these sessions (Citron et al., 2019).

\section{4) Governance}

One of the major goals of the NSOAPs is to increase the visibility and responsibility behind SOA care which necessitates strong governance. The plan specifies the tasks and responsibilities of NSOAP implementers at all levels of the health system, from the facility level to the national level. A national coordinator as well as a technical working group will engage with other departments and ministries on the national level to promote the NSOAP agenda and ensure the resources needed. Regional and council health management team representatives will collect and enhance data, guarantee coordinated integration of NSOAP activities in council plans and monitor implementation of NSOAP (Citron et al., 2019).

\section{5) Finance}

In order to secure the complete implementation and achievement of NSOAP objectives, sustainable finance mechanisms are essential. NSOAP funding will require cross-sectoral local, regional and national commitment and possible international assistance. The NSOAP outlines tactics for lobbying for financial assistance from current and new funding streams in order to receive the funding. Also, higher service delivery may result in increased usage of SOA services and, as a result, increased income from user fees can be the source of funding for hospital operations (Citron et al., 2019). 


\section{Six Surgical Indicators}

It is crucial to set a baseline when it comes to evaluating future policies and programs. The LCoGS met in 2015 to gather information on surgical care throughout the world and to come up with plans for enhancing access and quality. In order to provide a more accurate picture of a country's surgical quality, the Commission suggested that all nations monitor their system's six key surgical indicators which include access to timely essential surgery, specialist surgical workforce density, surgical volume, perioperative mortality rate (POMR), protection against impoverishing expenditure, protection against catastrophic expenditure. Three surgical domains are measured by them: readiness to offer surgical services, service volume and results, and financial risk. WHO and the World Bank have asked countries to gather and evaluate information on all six indicators to receive a current assessment of surgical treatment and enable international comparisons. Measuring these indicators enables not only baseline parameter calculation, but also continual monitoring and assessment (UNITAR, 2020).

1) Access to timely essential surgery: Everyone should have immediate access to emergency surgical treatments. The performance of a bellwether surgery predicts the success of many other critical surgical procedures. Two hours is the threshold for mortality from delivery complications.

2) Specialist surgical workforce density: Staffing availability and accessibility for health is a key element of surgical and anaesthetic care delivery.

3) Surgical volume: The number of surgical operations performed each year is a measure of needs that are met.

4) POMR: Surgical and anaesthetic safety are crucial parts of care delivery. Perioperative mortality includes fatalities in the operating room and in the hospital following the operation.

5) Protection against impoverishing expenditure: Every year, billions of individuals face financial ruin as a result of receiving surgical services. This is a surgery-specific variant of the World Bank's UHC goal.

6) Protection against catastrophic expenditure: Every year, billions of individuals face financial ruin as a result of receiving surgical services. This is a surgeryspecific variant of the World Bank's UHC goal (Global Surgery 2030, n.d.). 
〈Table 1〉 Six indicators of NSOAPs

\begin{tabular}{|c|c|c|c|}
\hline Number & Indicator & Description & Target \\
\hline 1 & $\begin{array}{l}\text { Access to timely } \\
\text { essential surgery }\end{array}$ & $\begin{array}{l}\text { Fraction of the population that can } \\
\text { access, within } 2 \text { hours, a hospital } \\
\text { capable of performing Caesarean } \\
\text { section, laparotomy, and open frac- } \\
\text { ture repair under appropriate ana- } \\
\text { esthetic. }\end{array}$ & $\begin{array}{l}\text { By 2030, each nation } \\
\text { must have at least } 80 \% \\
\text { coverage of basic surgical } \\
\text { and anaethetic services. }\end{array}$ \\
\hline 2 & $\begin{array}{c}\text { Specialist } \\
\text { (licensed) surgical } \\
\text { workforce density } \\
\text { (SAO density) }\end{array}$ & $\begin{array}{l}\text { Number of active specialist surgical, } \\
\text { anaesthetic, and obstetric physicians } \\
\text { per } 100,000 \text { population. }\end{array}$ & $\begin{array}{l}\text { By } 2030 \text {, every country } \\
\text { has at least } 20 \text { surgical, } \\
\text { anaesthetic, and obstetric } \\
\text { physicians per } 100,000 \\
\text { people. }\end{array}$ \\
\hline 3 & $\begin{array}{l}\text { Perioperative } \\
\text { mortality }\end{array}$ & $\begin{array}{l}\text { Before discharge or within } 30 \text { days, } \\
\text { the all-cause death rate in patients } \\
\text { who have had a procedure in an } \\
\text { operating theatre, divided by the } \\
\text { total number of procedures, express- } \\
\text { ed as a percentage. }\end{array}$ & $\begin{array}{l}\text { Tracking perioperative mor- } \\
\text { tality in } 80 \% \text { of nations } \\
\text { by } 2020 \text { and } 100 \% \text { of co- } \\
\text { untries by } 2030 \text {; in } 2020 \text {, } \\
\text { review global data and } \\
\text { create national objectives } \\
\text { for } 2030 \text {. }\end{array}$ \\
\hline 4 & $\begin{array}{l}\text { Total surgical } \\
\text { volume }\end{array}$ & $\begin{array}{l}\text { Procedures performed in an opera- } \\
\text { ting room per } 100,000 \text { people each } \\
\text { year. }\end{array}$ & $\begin{array}{l}80 \% \text { of nations tracking } \\
\text { surgical volume by } 2020 \text {, } \\
\text { and } 100 \% \text { of countries tra- } \\
\text { cking surgical volume by } \\
2030 \text {; a minimum of } 5,000 \\
\text { operations per } 100,000 \\
\text { people by } 2030 \text {. }\end{array}$ \\
\hline 5 & $\begin{array}{l}\text { Protection against } \\
\text { impoverishing } \\
\text { surgical care }\end{array}$ & $\begin{array}{l}\text { Share of households safeguarded } \\
\text { from poverty by direct out-of-pocket } \\
\text { payments for surgical and anaes- } \\
\text { thetic treatment. }\end{array}$ & $\begin{array}{l}100 \% \text { Protection from out- } \\
\text { of-pocket expenditures for } \\
\text { necessary surgical and } \\
\text { anesthetic services by } \\
2030 \text {. }\end{array}$ \\
\hline
\end{tabular}

Note: NSOAP, National Surgical, Obstetric, Anaesthesia Plan.

\section{MACROECONOMICS OF SURGICAL CARE: THE COST OF DOING NOTHING}

Many academics developed a case for investing in surgical care based on the macroeconomics of surgical care and the cost of inactivity. For decades, they 
have researched the relationship between health and economic output, developing a variety of models. We would like to offer these economic models, which show that the economic costs of inactivity are substantial.

\section{Economic Welfare Perspective}

Economic well-being is contingent on people's capacity to consume goods and services, their ability to do what they want in their leisure time, and their general health. Disease and injury not only have detrimental influence on people's health, but they also have an impact on their capacity to consume and enjoy life. They also lower utility in other ways, such as out-of-pocket health care costs (Alkire, 2019). A case control study on cataract surgery in the Philippines discovered that the surgery successfully enhanced the standard of life in the intervention group. When compared to the control group, the average increase in monthly per capita spending among patients who underwent the operation was 88 percent (Kuper et al., 2010).

\section{Economic Output Perspective}

A new economic approach investigates the link between a country's population health and its economic production. At the macro level, the elements of economic production include the ability of households to consume products, resources of companies and governments to invest in human and physical capital and labor supply productivity. Disease and injury can have an influence on macroeconomic performance by determining how much governments must spend on health at the expense of infrastructure or education investments. Household consumption is also influenced by out-of-pocket health care costs. Furthermore, poor health and premature mortality have a severe impact on labor supply and productivity (Alkire, 2019). 


\section{Estimating the Macroeconomic Burden of Disease}

\section{1) Value of lost output model}

The value of lost output (VLO) approach estimates the impact of disease on a country's market economy by calculating the amount of potential GDP loss incurred during the disease process. The VLO model is based on the CobbDouglas function, which relates a country's GDP to its capital stock, labor supply, and technical advancement. Researchers can use this model to analyze how a disease or collection of disease affects a country's labor supply and physical stock, as well as how those changes impact GDP. According to the VLO model, 128 nations were expected to have GDP losses owing to surgical disease over a 15-year period (Alkire, 2019). The estimates are that if inaction persists, the world GDP will decrease by $\$ 22$ trillion in the next 15 years, with developing nations losing $\$ 12.3$ trillion (Alkire, 2019). Low-income countries and LMICs run the risk of losing the most in terms of GDP - up to $2 \%$ (Alkire, 2019). A research (Breman et al., 2001) found a 1.3 percent loss in GDP in nations with severe malaria, which makes a $2 \%$ loss quite a big blow for the LMICs.

\section{2) Value of lost welfare model}

When applying the Value of Lost Welfare (VLW) approach, the non-market losses, such as monetary value of excellent health, are examined. This method is based on a notion known as the value of statistical life (VSL). The notion of VSL is commonly used in environmental economics to perform benefit-cost analysis, but it is increasingly being applied in health economics. The crux of VLS is determining how much people are prepared to pay to lower their mortality by a tiny percentage and then translating that amount to a VSL. For example, if a person is willing to invest $\$ 6$ to lower his or her probability of dying this year by 1 in $1,000,000$, the person's VLS is about $\$ 6.1$ in $1,000,000$ or $\$ 6,000,000$ (Alkire, 2019).

After analyzing the data for 175 countries, according to the model, highincome nations will lose the most in terms of equivalent percentage of GDP (Alkire, 2019). This is because neoplasms are presently more common in highincome countries. If that category is removed from the model, low-income 
countries will be the most influenced. Due to ongoing epidemiological change in LMICs, LMICs will be expected to bear the brunt of this burden as well. In the coming year, LMICs are estimated to lose $\$ 4$ trillion in economic wellbeing attributable to surgical disease (Alkire, 2019).

\section{THE NSOAP MODELS: CENTRALIZED AND PROVINCIAL MODELS}

Countries worldwide have begun to develop NSOAPs in order to extend access to SAO care in a sustainable manner. In this paper, we present cases of Zambia and Pakistan which each represent the centralized and decentralized model. These countries concentrated on resolving health system deficiencies, incorporating surgical policies into wider national policies and including and consulting all key stakeholders in the planning process according to their respective model.

\section{Zambia: Centralized Model}

In Zambia, the NSOAP process began in 2010 after an assessment of maternal mortality rates revealed that objectives were not being met and that the most significant impediment was a condition associated with delivery that necessitated surgical intervention. A complete examination of every surgical institution in Zambia that followed showed deficiencies in every aspect of assessment. Emmanuel Makasa, the then health attache for Zambia, collaborated with the other member states of the WHO on the talks that resulted in WHA Reolution 68.15 in 2015. Zambia sought to develop the NSOAP with this worldwide commitment. They collaborated with a variety of regional players and received significant support from high-level policy makers. Zambia's NSOAP planners elaborated on the LCoGS framework by including the area of governance, and Zambia's NSOAP was unveiled at the WHA in 2017 (Makasa, 2019).

A few difficulties encountered in developing Zambia's NSOAP stemmed from the fact that Zambia was a pioneer country to begin the NSOAP process. Due to this, it lacked the experience of other countries from which it could learn from. The development process itself necessitates money for administrative expenditures, 
event planning and meeting space for stakeholders. The $\mathrm{MoH}$ assisted in covering a portion of the expenditures incurred from Zambian NSOAP procedure. Nonetheless, funding Zambian NSOAP implementation has been a considerable issue due to the difficulty in mobilizing internal and foreign resources. The NSOAP was incorporated into the national health sector plan in order to benefit from local resources, and it has been moderately effective in channeling some money toward surgical treatment. A new legislation developed a national health insurance authority with the expectation that health insurance will assist people reduce their financial burden (Makasa, 2019).

\section{Pakistan: Provincial Model}

The NSOAP method is adaptable and modified to fit Pakistan's health governance structure and operational dynamics due to Pakistan's federal-provincial system. The National Vision for Surgical Care 2025 (NVSC2025) was developed by the Ministry of National Health Services, Regulation and Coordination (MoNHSR\&C). Because surgical care was not given a high priority, NVSC2025 plans to ensure that such a gap is filled (UNITAR, 2020).

A National Stakeholders' Conference was held in Islamabad in November 2018, jointly organized by the MoNHSR\&C and Indus Health Network. Stakeholders in federal and provincial health agencies, the corporate and public sectors, national and international academic institutions, and non-profit organizations participated. At this meeting, a consensus statement was produced, which served as a foundation for the NVSC document that was later created. The paper serves as a blueprint for each province's Department of Health to create a Provincial Surgical, Obstetric, and Anaesthesia Plan (PSOAP) that is tailored to the province's particular surgical needs. Pakistan has implemented the NSOAP framework in two different but interconnected phases that are well aligned with the country's devolved government system. In order to build NVSC2025, the first ministerial and stakeholder participation was done in tandem with a comprehensive gap assessment in Pakistan. These processes have been duplicated at the provincial level, after which tailored PSOAPs will be drafted, with M\&E, governance, and costing components defined in accordance with each province's needs and 
resources (UNITAR, 2020).

While this method seems to be more time-consuming with involvement of number of stakeholders, it fits within the country's governmental structure effectively. Given the vast population this intervention intends to cover, it is believed that ownership and execution at the provincial level will result in superior long-term effects (UNITAR, 2020).

\section{COVID-19 AND SURGICAL CARE}

The article demonstrated in earlier parts why surgical care should be prioritized in the global agenda in terms of welfare, economic growth, and health - particularly focusing on attainment of two major global goals, UHC and SDGs. Aside from these reasons, LMICs could reframe surgical system strengthening as part of pandemic preparedness strategy. This can only be done via expanding surgical capacity (Park et al., 2020b). This is clearly demonstrated by the way the surgical system, with its "staff, stuff, space and system" is being repurposed for the treatment of COVID-19. Countries with professional surgical competence are likely to have resilient health systems, which helps coping with worldwide epidemics such as COVID-19.

The incorporation of essential and emergency surgical care into district hospitals serves as a facilitator, increasing the ability to provide additional health care services, other than just surgeries (The PLoS Medicine Editors, 2008). Because of such an intricacy (Farmer, 2008), the provision of safe surgery and anesthesia indicates the presence of a responsive health care system's staff, stuff, space and systems (BostonGlobe, 2014, Meara et al., 2015). A system such as this is capable of not just delivering surgical care, but also of managing a wide variety of health issues, such as malnutrition, obstetric difficulties, trauma, disaster response, and infectious disease epidemics and pandemics (Kucchal et al., 2020). According to World Bank President Jim Kim's remarks at the Commission's first meeting, "surgery is an indivisible, indispensable part of health care" (Shrime et al., 2015).

The COVID-19 pandemic illustrated worldwide the value of surgical and anesthetic services in pandemic response. COVID-19 made no distinction between 
wealthy and low-income countries as it affected any country with inadequate critical care capacity worldwide. On the contrary, certain countries with appropriate surgical capability were able to react promptly (Kucchal et al., 2020). Surgeons, scrub nurses, and paramedics were re-deployed to pandemic activities where surgical capacity was confined to necessary emergency and category-1 operations (Ahmed et al., 2020). By lowering baseline operating volumes, Intensive Care Unit (ICU) resources for the patients with fatal symptoms were freed up (Ahmed et al., 2020). Unused anaesthesia machines were repurposed as ward ventilators (Rajan \& Joshi, 2020). Personal Protective Equipment (PPE) normally kept for operational purposes functioned as a backup for PPE resources during case increases, until more supplies could be secured. Surge capacity gained through provision of surgical and anesthesia services proved critical in a successful pandemic response (Kucchal et al., 2020). Equipping surgical beds, ICUs, and operating theaters in tandem with a cadre of trained staff meets the population's huge unmet surgical demands while also providing urgent treatment capacity in the times of a pandemic (Park et al., 2020b).

\section{DISCUSSION}

Despite the belief that surgical treatment is complicated and expensive, surgery has been proved to be cost-effective. Scaling up surgical care to address the surgical burden of illness in surgical treatment is one of the most economical interventions in public health, comparable with well-known cost-effective interventions (UNITAR, 2020). This means that there is no reason to delay adopting surgical interventions into the national health policies of LMICs and the most appropriate tool for this is the NSOAPs.

To achieve the SDGs, SOA care is necessary Patient-focused surgical care integration is necessary to fulfill the SDGs. Increased support for SOA care is capable of making significant impact on most of the SDGs, both in regard to poverty reduction and better health and productivity. Six of the SDGs are especially dependent on the improvement of SOA: SDGs related to good health and well- being (SDG 3), SDGs related to gender equality (SDG 5), and SDGs related to economic improvement, including an end to poverty (SDG 1), decent 
work and economic growth (SDG 8), reduced inequalities (SDG 10) and creating the partnerships necessary to make this a reality (SDG 17). Among six goals, the goal that is most directly associated with the SOA care is SDG 3: Good Health and well-being (UNITAR, 2020).

Because surgical treatment is necessary for a hefty portion of global burden of illness, it is impossible to fulfill SDG 3 on health and well-being in LMICs without undertaking this burden. SDG 3 has nine objectives that are directly associated with SOA care. Among the nine objectives, four of them cannot be met unless SOA care is improved: 3.1 (reduce maternal mortality), 3.2 (reduce infant and under -5 mortality), 3.4 (reduce premature deaths from NCDs) and 3.6 (reduce the number of deaths and disabilities from road traffic accidents). The target 3.8 of UHC is particularly significant, since it serves as the groundwork for all other targets. It encompasses increased SOA care, which is required for reaching other objectives. To improve the maternal mortality ratio to less than 70 per 100,000 population (SDG 3.1) and the perinatal death rate to 12 per 1000 live births, scaling up SOA care will be imperative (SDG 3.2). Empirical data (Betran et al., 2015) shows that maternal and perinatal mortality will be reduced when Comprehensive Emergency Obstetric and Newborn Care (CEmONC) is available. Maternal mortality due to obstructed labour occur in around $8 \%$ of cases, and some of these women end up with obstetric fistula, a disabling and stigmatized obstetrical complication. The research done by Molina et al. (2016) studied over 22.9 million caesarean sections and found that having a national caesarean section rate up to $19 \%$ was associated with a reduced newborn death rate (2016). Not only obstructed labor but also ectopic pregnancies, obstetric fistula repair, cervical cancer, and other gynecological tumors all require surgical treatment (UNITAR, 2020).

SDG 3.4 aspires to curtail the premature mortality rate due to non-communicable diseases by one-third. As previously stated, a large percentage of malignancies, including $60 \%$ of all cancers will necessitate surgery and a robust perioperative surgical system (UNITAR, 2020). To help treat cardiovascular illness, surgical procedures such as minimally invasive or open cardiac and vascular methods are essential. The neurosurgical capability is also necessary to help alleviate the related health issues caused by a stroke (UNITAR, 2020).

Another specific goals of the SDGs, is to reduce the number of fatalities and 
injuries caused by road traffic accidents by half. For the treatment of trauma patients, comprehensive SOA care, as well as robust pre-hospital and emergency care systems, are necessary. Many of those who do not require intervention in the operating theatre will require surgery and anaesthetic services for correct evaluation and stabilization (UNITAR, 2020).

Furthermore, SOA care is necessary to meet UHC targets and primary health care coverage. Following the unanimous passage of resolution WHA 68.15 in 2015, emergency and essential surgery and anaesthetic treatment are major elements of UHC. UHC is defined by WHO as "ensuring that all people have access to needed promotive, preventive, curative, and rehabilitative health services, of sufficient quality to be effective, while also ensuring that people do not suffer financial hardship when paying for these services." $80 \%$ of all basic health care and $100 \%$ protection from out-of-pocket expenditures by 2030 are defined as objectives for universal coverage by World Bank and WHO. To reach the objectives for UHC, we will need to expand the number of people who have access to SOA care by $250 \%$ by 2030 (UNITAR, 2020). The best estimate is that up to $80 \%-90 \%$ of all surgical problems may be handled by district hospitals (UNITAR, 2020), so SOA care should be implemented in all attempts to enhance primary health care. To recognize this, the most effective method to increase global wellbeing was "improved surgical treatment at the district hospital," (The PLoS Medicine Editors, 2008) as revealed in the Copenhagen Consensus.

For SOA care to function well, the cooperation of various components of the health care system is needed. In addition to the operating room environment and postoperative rehabilitation capability, other aspects include community education, prehospital care, emergency department care, strong consumable supply chains and laboratory services. Because many of these services are shared, increasing SOA care capacity can also enhance the functioning of several other aspects in the hospital. A stable supply of antibiotics for surgery, for example, not only helps to decrease postoperative sepsis in surgical patients, but it will also help reduce under-5 mortality from pneumonia. Critical care capacity combined with improved anaesthesia increases the volume and complexity of surgical treatment, but it also allows the provision of life-saving medical care for patients who are critically ill (UNITAR, 2020). 


\section{SUGGESTIONS}

It is critical to gain Ministry support and ownership. The first and perhaps most crucial step in effectively implementing an NSOAP is garnering support from the MoH. To increase the likelihood of NSOAP incorporation into health strategic plan (NHSP) and NSOAP execution, buy-in, support, and leadership from the $\mathrm{MoH}$ are essential. $\mathrm{MoH}$ understands country priorities, present health care environment, financial and resource capacity and implementation capabilities. Ministries are also in charge of policy creation and drafting, as well as carrying the most up-to-date knowledge of current programs and priorities, which can assist to minimize fragmentation and duplication. It is beneficial to determine where the NSOAP will be located within the $\mathrm{MoH}$ early in the process. Practically this can assist in establishing sustainability of leadership, governance, and accountability for the NSOAP within the $\mathrm{MoH}$, particularly during the times of government transition (UNITAR, 2020).

A thorough situation analysis and baseline evaluation is essential for creating evidence-based policy. A thorough review of a country's surgical system contributes to defining the baseline status and identifying key gaps in treatment. This can be accomplished through taking a number of approaches, including on-the-ground hospital inspections, literature studies, and analysis of existing national data. The six surgical measures proposed by LCoGs and included in the WHO core 100 Health Indicators in 2015 and 2018 might serve as a suitable starting point (UNITAR, 2020).

It is critical to include diverse stakeholders and establish priorities. A wider group of stakeholders in the planning process, including the clinical providers, professional and civil societies, academic institutions, funders and implementers, should be invited to represent the opinions and expertise of various stakeholders. NSOAPs target the entire surgical system, which may be split into six key areas to be addressed by several stakeholder groups. Taking a methodical approach to tackling each area can aid in guaranteeing that the strategy is comprehensive. Such an approach may begin with a discussion of baseline assessments, then identification of issues and prioritization of possible solutions, 
defining of goals and targets, and finally offering of a monitoring and evaluation strategy (UNITAR, 2020).

\section{CONCLUSION}

To sum up, to achieve the UHC and SDGs by 2030 increasing the surgical capacity of LMICs can make a significant contribution towards it. Although surgical care is the area that does not get enough attention it deserves, by integrating SOA care into national policies of LMICs, millions of people's lives will be saved, and billions in economic losses averted. Also, increasing the surgical capacities in LMICs in the times of global pandemic will help build resilient health system and prepare for future pandemics. It is imperative that donor countries, including South Korean government, take part in the global surgery movement including the NSOAP development by countries. This will promote the strengthened health system globally.

\section{REFERENCES}

Ahmed, S., Tan, W. L. G., \& Chong, Y. L. (2020). Surgical response to COVID-19 pandemic: A Singapore perspective. Journal of the American College of Surgeons, 2306), 1074-1077.

Alkire, B. (2019). Macroeconomics of surgical care: The cost of doing nothing. In Proceedings of the Harvard Medical School Center for Global Health Delivery. Dubai, United Arab Emirates.

Betran, A. P., Torloni, M. R., Zhang, J., Ye, J., Mikolajczyk, R., Deneux-Tharaux, C., Oladapo, O. T., Souza, J. P., Tunçalp, Ö., Vogel, J. P., \& Gülmezoglu, A. M. (2015). What is the optimal rate of caesarean section at population level? A systematic review of ecologic studies. Reproductive Health, 12(1), 57.

BostonGlobe.Com. (2014). Ebola's front lines: Countries need tools to treat patients in their homes and communities. Retrieved from https://www.bos tonglobe.com/opinion/2014/09/23/responding-ebola-countries-need-staff-stuff -space-and-systems/ugSFKkOw9S7Ser0p8PGeOK/story.html 
Breman, J., Egan, A., \& Keusch, G. (2001). The intolerable burden of malaria: A new look at the numbers. The American Journal of Tropical Medicine and Hygiene, 64(1_suppl), iv. https://doi.org/10.4269/ajtmh.2001.64.iv

Chao, T. E., Sharma, K., Mandigo, M., Hagander, L., Resch, S. C., Weiser, T. G., \& Meara, J. G. (2014). Cost-effectiveness of surgery and its policy implications for global health: A systematic review and analysis. The Lancet Global Health, 2(6), E334-E345.

Citron, I., Sonderman, K., Subi, L., \& Meara, J. G. (2018). Making a case for national surgery, obstetric, and anesthesia plans. Canadian Journal of Anesthesial Journal Canadien d'anesthésie, 66(3), 263-271.

Citron, I., Jumbam, D., Dahm, J., Mukhopadhyay, S., Nyberger, K., Iverson, K., Akoko, L., Lugazia, E., D'Mello, B., Maongezi, S., Nguhuni, B., Kapologwe, N., Hellar, A., Maina, E., Kisakye, S., Mwai, P., Reynolds, C., Varghese, A., Barash, D., Steer, M., Meara, J., \& Ulisubisya, M. (2019). Towards equitable surgical systems: Development and outcomes of a national surgical, obstetric and anaesthesia plan in Tanzania. BMJ Global Health, 4(2), e001282.

Dell, A. D. (2016). Global surgery - socioeconomic and geographic maldistribution of surgical resources. Retrieved from https://open.uct.ac.za/bitstream/handle/ 11427/22796/thesis_hsf_2016_dell_angela_june.pdf?sequence=4\&isAllowed=y

Farmer, P. E. (2008). Surgery and global health: A view from beyond the OR. World Journal of Surgery, 32(4), 533-536.

Global Surgery 2030. (n.d.). Core indicators for monitoring universal access to safe, affordable surgical and anaesthesia care when needed. Global Health Delivery Online. Retrieved from https://www.ghdonline.org/uploads/Indicators_ GS2030.pdf

Global Surgery Foundation (n.d.). Why surgery? Retrieved from https://www.global surgeryfoundation.org/why

Gyedu, A. (2017). The brain drain myth: Retention of specialist surgical graduates in East, Central and Southern Africa 1974-2013. World Journal of Surgery, 41(12), 3054.

Kucchal, T., Pigeolet, M., Rolle, M., Johnson, W. D., \& Park, K. B. (2020). International organisations in global surgery: Challenges and opportunities. Journal of Public Health and Emergency, 4, 35. 
Kuper H, Polack S, Mathenge W, Eusebio C, Wadud Z, Rashid M, \& Foster, A. (2010) Does cataract surgery alleviate poverty? Evidence from a multi-centre intervention study conducted in Kenya, the Philippines and Bangladesh. PLoS One, 5(11):e15431.

Makasa, E. (2019). Milestones in NSOAP development and implementation in Africa. In Proceedings of the Harvard Medical School Center for Global Health Delivery. Dubai, United Arab Emirates.

Meara, J. G., Leather, A. J. M., \& Farmer, P. E. (2019). Making all deaths after surgery count. The Lancet, 393(10191), P2587.

Meara, J. G., Leather, A. J. M., Hagander, L., Alkire, B. C., Alonso, N., Ameh, E. A., Bickler, S. W., Conteh, L., Dare, A. J., Davies, J., Mérisier, E. D., El-Halabi, S., Farmer, P. E., Gawande, A., Gillies, R., Greenberg, S. L. M., Grimes, C. E., Gruen, R. L., Ismail, E. A., Kamara, T. B., Lavy, C., Ganbold, L., Mkandawire, N. C., Raykar, N. P., Riesel, J. N., Rodas, E., Rose, J., Roy, N., Shrime, M. G., Sullivan, R., Verguet, S., Watters, D., Weiser, T. G., Wilson, I. H., Yamey, G., \& Yip, W. (2015). Global surgery 2030: Evidence and solutions for achieving health, welfare, and economic development. Surgery, 158(1), 3-6.

Meara, J. G., \& Greenberg, S. L. M. (2015). The lancet commission on global surgery global surgery 2030: Evidence and solutions for achieving health, welfare and economic development. Surgery, 157(5), 834-835.

Molina, G., Weiser, T. G., Lipsitz, S. R., Esquivel, M. M., Uribe-Leitz, T., Azad, T., Shah, N., Semrau, K., Berry, W. R., Gawande, A. A., \& Haynes, A. B. (2016). Relationship between cesarean delivery rate and maternal and neonatal mortality. Obstetric Anesthesia Digest, 36(4), 171-172.

National Academies of Sciences, Engineering, and Medicine. (2017). Global health and the future role of the United States. Washington, DC: National Academies Press.

Nyberger, K., Jumbam, D. T., Dahm, J., Maongezi, S., Makuwani, A., Kapologwe, N. A., Nguhuni, B., Mukhopadhay, S., Iverson, K. R., Maina, E., Kisakye, S., Mwai, P., Hellar, A., Barash, D., Reynolds, C., Meara, J. G., \& Citron, I. (2018). The situation of safe surgery and anaesthesia in Tanzania: A systematic review. World Journal of Surgery, 43(1), 24-35. 
Park, K. B., Kanmounye, U. S., \& Lartigue, J. W. (2020). Global neurosurgery in the time of COVID-19. Neurospine, 17(2), 348-350.

Peck, G. L., \& Hanna, J. S. (2018). The national surgical, obstetric, and anesthesia plan (NSOAP): Recognition and definition of an empirically evolving global surgery systems science comment on "global surgery - informing national strategies for scaling up surgery in sub-Saharan Africa”. International Journal of Health Policy and Management, Х(12), 1151-1154.

Peters, A. W., Roa, L., Rwamasirabo, E., Ameh, E., Ulisubisya, M. M., Samad, L., Makasa, E. M., \& Meara, J. G. (2020). National surgical, obstetric, and anesthesia plans supporting the vision of universal health coverage. Global Health: Science and Practice, 8(1), 1-9.

World Health Organization. (2021). Primary health care. Retrieved from https:// www.who.int/news-room/fact-sheets/detail/primary-health-care

Prince, C. (2021). WHO calls for more investment in primary health care; 'world is far behind' in reaching universal health coverage. Health Policy Watch. Retrieved from https://healthpolicy-watch.news/86733-2/

Rajan, N., \& Joshi, G. P. (2020). COVID-19: Role of ambulatory surgery facilities in this global pandemic. Anesthesia \& Analgesia, 131(1), 31-36.

Roa, L., Jumbam, D. T., Makasa, E., \& Meara, J. G. (2019). Global surgery and the sustainable development goals. British Journal of Surgery, 100(2), e44-e52.

Roa, L., Peters, A. W., \& Meara, J. G. (2019). National surgical, obstetric and anesthesia planning for high-level global, regional, and country authorities and funders. In Proceedings of the Harvard Medical School Center for Global Health DeliveryDubai. Dubai, United Arab Emirates.

Shrime, M. G., Bickler, S. W., Alkire, B. C., \& Mock, C. (2015). Global burden of surgical disease: An estimation from the provider perspective. The Lancet Global Health, 3, s8-S9.

THET. (n.d.a). Global surgery - the 'neglected stepchild of global health'. Retrieved from https://www.thet.org/global-surgery-neglected-stepchild-global-health/

Tanzania service availability and readiness assessment (SARA) 2012. (2013). Ifakara Health Institute.

The PLoS Medicine Editors. (2008). A crucial role for surgery in reaching the UN millennium development goals. PLoS Medicine, 5(8), e182. 
Truché, P., Shoman, H., Reddy, C. L., Jumbam, D. T., Ashby, J., Mazhiqi, A., Wurdeman, T., Ameh, E. A., Smith, M., Lugazia, E., Makasa, E., Park, K. B., \& Meara, J. G. (2020). Globalization of national surgical, obstetric and anesthesia plans: The critical link between health policy and action in global surgery. Global Health 16(1), 1.

UNITAR. (2020). National surgical, obstetric and anaesthesia planning manual. Geneva, Switzerland: United Nations Institute for Training and Research (UNITAR). Weiser, T. G., Regenbogen, S. E., Thompson, K. D., Haynes, A. B., Lipsitz, S. R., Berry, W. R., \& Gawande, A. A. (2008). An estimation of the global volume of surgery: A modelling strategy based on available data. The Lancet, 372(9633), 139-144.

World Bank. (2015). World bank surgical indicators. Washington, DC: World Bank. World Health Organization. (2015). 100 core health indicators 2015. Geneva, Switzerland: World Health Organization.

World Health Organization. (2018). 100 core health indicators 2018. Geneva, Switzerland: World Health Organization.

World Health Organization. (2021a). Action framework for safe and affordable surgery in the Western Pacific Region (2021-2030). Manila, Philippines: WHO Regional Office for the Western Pacific.

World Health Organization. (2021b). Universal health coverage [UHC]. Retrieved from https://www.who.int/news-room/fact-sheets/detail/universal-health-coverage(uhc) 